2

Supporting Information for

\title{
Entropy-Driven Aggregation of Titanium Dioxide Nanoparticles in Aquatic Environment
}

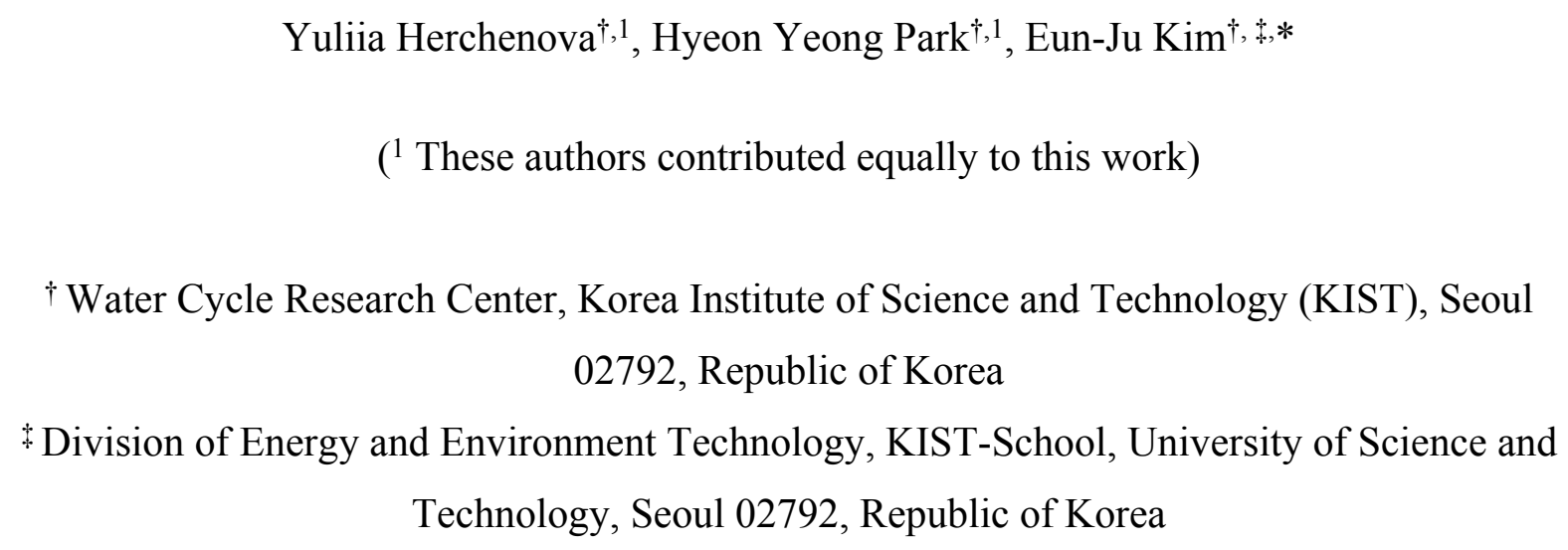




\section{(a)}

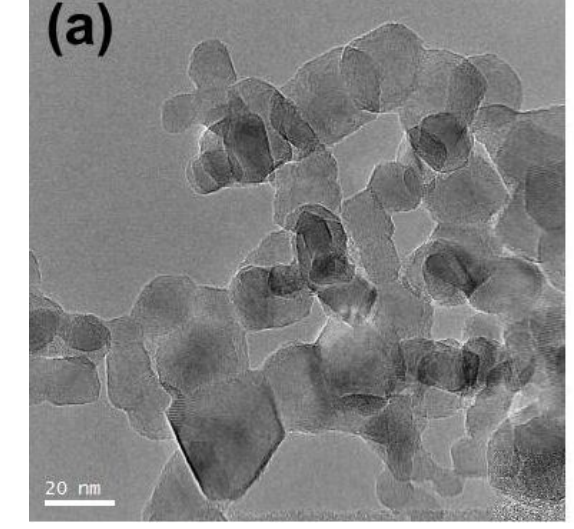

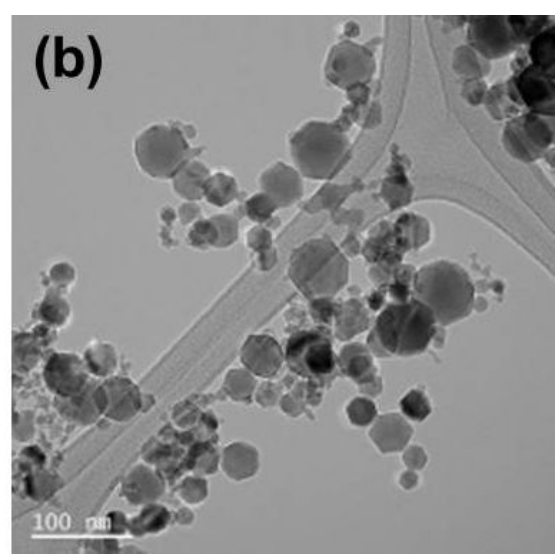

35

36 Figure S1. TEM images of (a) $\mathrm{TiO}_{2}$ and (b) hematite(Hem).

37

38

39

40

41

42

43

44

45

46

47

48

49 


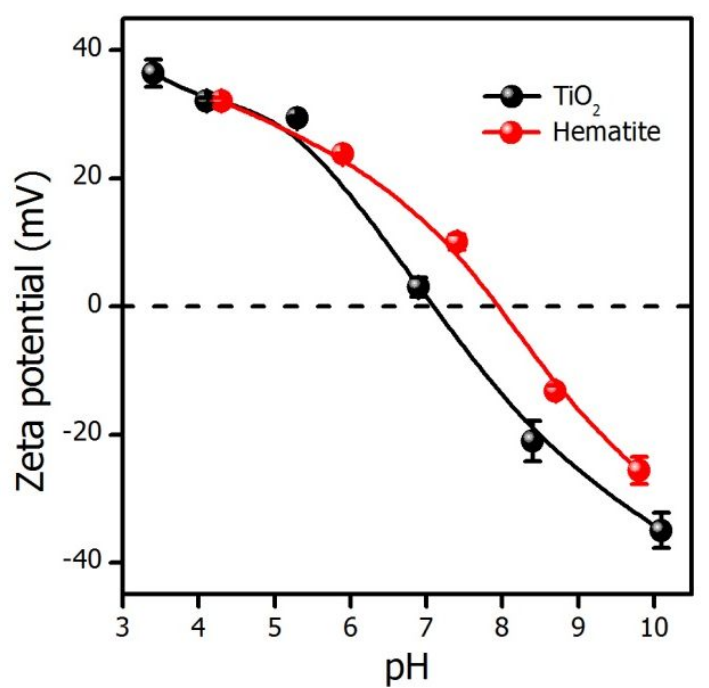

Figure S2. Zeta potentials of $\mathrm{TiO}_{2}$ and Hem as a function of $\mathrm{pH}$ in the presence of $10 \mathrm{mM}$ $54 \mathrm{NaCl}$. 


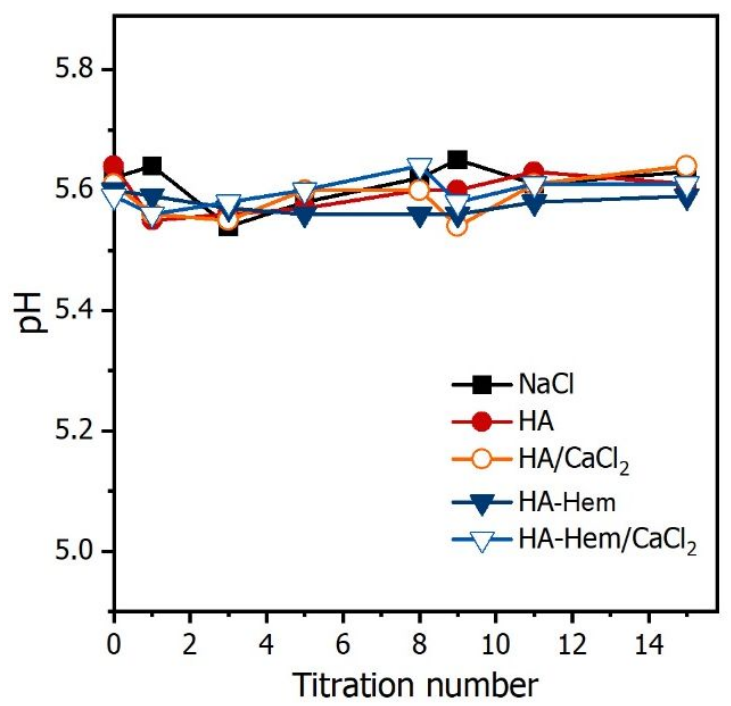

Figure S3. pH changes in $\mathrm{TiO}_{2}$ suspension during the titration experiment.

70 


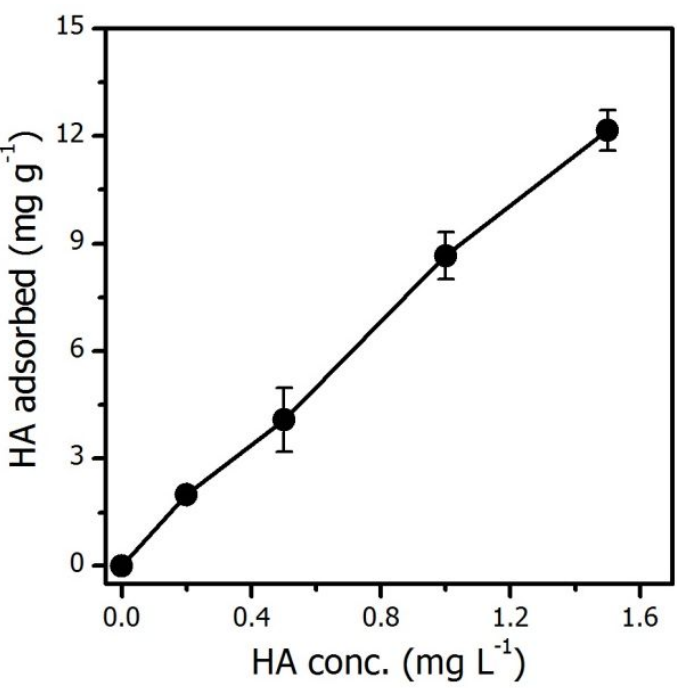

Figure S4. Amount of HA adsorbed by $\mathrm{TiO}_{2}$. 


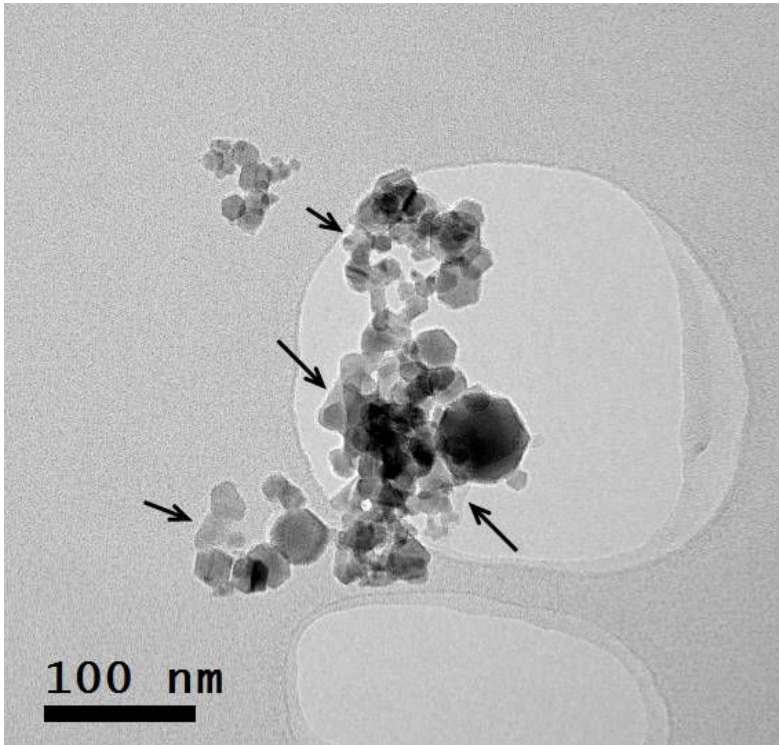

100

Figure S5. Representative TEM image of $\mathrm{HA}-\mathrm{Hem} / \mathrm{TiO}_{2}$ aggregate observed in the presence of $\mathrm{HA}\left(1 \mathrm{mg} \mathrm{L}^{-1} \mathrm{DOC}\right)$ and $2 \mathrm{mM} \mathrm{CaCl}_{2}$ at $\mathrm{pH}$ 5.6. Arrows indicate some HA aggregates.

103

104

105

106

108

109

110

111

112 


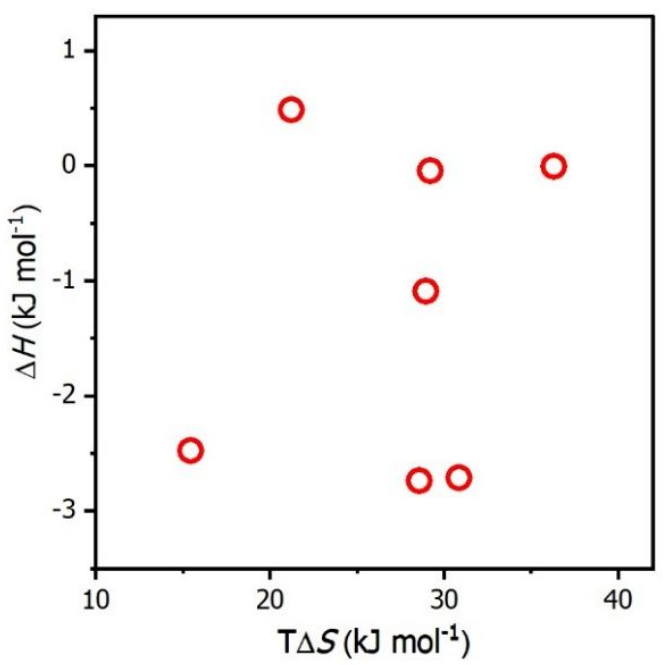

116 Figure S6. Plot of entropy versus enthalpy for experimental systems.

117 